\title{
ANALISIS DAN PERANCANGAN E-COMMERCE BUSINESS TO CONSUMER (B2C) DENGAN MENGGUNAKAN METODE SQUARE
}

\author{
FIQIH ISMAWAN \\ ABDUL MUFTI \\ BONDAN DWI HATMOKO \\ Program Studi Informatika \\ Fakultas Teknik dan Ilmu Komputer \\ Universitas Indraprasta PGRI
}

Jl. Nangka No. 58 C, Tanjung Barat, Jagakarsa, Jakarta Selatan 12530

Email:vQ.ismaone@gmail.com, abdul.mufti@gmail.com, bondan_dwi_hatmoko@yahoo.com

\begin{abstract}
Abstrak. Berkembangnya dunia TIK yang sangat pesat yang membuat semua orang ketergantungan dengan teknologi informasi yang dapat mendukung semua aspek kehidupan dalam menunjang kinerja operasional dan memberikan keuntungan yang sangat baik bagi penggunanya. Selain itu penggunaan TIK mampu menjadikan kekuatan terhadap persaingan bisnis bagi perusahaan. Teknologi informasi yang sedang banyak digunakan yaitu sistem aplikasi berbasis website dan sistem aplikasi mobile phone. Hadirnya teknologi e-commerce membuat aturan perdagangan atau konsep jual-beli di internet semakin mudah dan praktis, pembeli dan penjual dipertemukan di dalam satu sistem dan terhubung jaringan internet satu sama lainnya. Dengan banyaknya pilihan sistem aplikasi e-commerce berbasis website dan sistem aplikasi mobile phone yang dapat digunakan dalam aturan perdagangan atau konsep jualbeli, maka perlu diperhatikan bagaimana mekanisme keamanan data pembeli dan proses transaksi dapat dilakukan dalam satu sistem e-commerce. Permasalahan kemananan data costumer dan data transaksi sangatlah riskan serta berdampak luas terhadap keamanan sistem aplikasi yang di rancang. Tujuan penelitian ini diharapkan dapat membantu organisasi atau perusahaan menjamin keamanan dan keberlangsungan sistem dan aplikasi khususnya sistem aplikasi e-commerce. Penelitian ini di bangun oleh metode System Quality Engineering Requirement (SQUARE) dalam menganalisis dan perancangan sistem aplikasi e-commerce Business to Costumer (B2C). Hasil dari penelitian ini berupa rancangan prototipe aplikasi $e$ commerce sesuai dengan proses analisis metode System Quality Engineering Requirement (SQUARE).
\end{abstract}

Kata Kunci: e-commerce, metode SQUARE, jual beli, keamanan sistem.

Abstract. The development of the world of ICT world has made everyone dependent on information technology that can support all aspects of life in supporting operational performance and providing excellent benefits for its users. In addition, the use of ICTs is able to make a force against business competition for companies. Information technology that is being used is a website-based application system and a mobile phone application system. The presence of e-commerce technology makes trading rules or the concept of buying and selling on the internet increasingly easy and practical, buyers and sellers are reunited in one system and connected to the internet by one another. With the many choices of website-based e-commerce application systems and mobile phone application systems that can be used in trade rules or the concept of buying and selling, it should be noted how the buyer's data security mechanism and transaction processes can be done in an e-commerce system. The issue of customer data security and transaction data is very risky and has a broad impact on the application system security that is designed. The purpose of this study is expected to help organizations or companies ensure the security and sustainability of systems and applications, especially ecommerce application systems. This research was developed by the System Quality Engineering 
Requirement (SQUARE) method in analyzing and designing an e-commerce Business to Customer (B2C) system. The results of this study are in the form of a prototype e-commerce application according to the analysis process of the System Quality Engineering Requirement (SQUARE) method.

Keywords: e-commerce, SQUARE method, buy and sell, system security

\section{PENDAHULUAN}

Setiap orang biasanya selalu ingin memiliki sebuah usaha dalam bidang apa saja yang dapat memberikan penghasilan bagi orang tersebut, bahkan bagi perusahaan atau grup tertentu. Usaha dalam bidang apa saja bisa dikatakan bisnis, umumnya bisnis lebih diasumsikan kepada grup atau perusahaan yang dikelola dengan manajemen seperti yang sekarang kita lihat sedang marak dalam kehidupan sekarang ini. Seiring dengan perkembangan bisnis, setiap pelaku bisnis melakukan inovasi dalam strategi marketing dan pelayanan. Salah satu yang sedang populer dalam mendukung bisnis yaitu sistem e-commerce.

Berkembangnya dunia TIK yang sangat pesat yang membuat semua orang ketergantungan dengan teknologi informasi yang dapat mendukung semua aspek kehidupan dalam menunjang kinerja operasional dan memberikan keuntungan yang sangat baik bagi penggunanya. Selain itu penggunaan TIK mampu menjadikan kekuatan terhadap persaingan bisnis bagi perusahaan. Teknologi informasi yang sedang banyak digunakan yaitu sistem aplikasi berbasis website dan sistem aplikasi mobile phone. Hadirnya teknologi e-commerce membuat aturan perdagangan atau konsep jual-beli di internet semakin mudah dan praktis, pembeli dan penjual dipertemukan di dalam satu sistem dan terhubung jaringan internet satu sama lainnya. Dengan banyaknya pilihan sistem aplikasi e-commerce berbasis website dan sistem aplikasi mobile phone yang dapat digunakan dalam aturan perdagangan atau konsep jualbeli, maka perlu diperhatikan bagaimana mekanisme keamanan data pembeli dan proses transaksi dapat dilakukan dalam satu sistem e-commerce. Permasalahan kemananan data costumer dan data transaksi sangatlah riskan serta berdampak luas terhadap keamanan sistem aplikasi yang di rancang.

Penelitian ini merujuk pada penelitian dengan objek e-government mobile dan web, perangkat lunak Justinmind dan Mockplus (Albaar, 2016), parameter komparasi penelitian ini menggunakan metode square yakni Definitions, Safety \& Security Goals, System Architecture,

Use Cases, Misuse Cases, Attack Tree, Prioritization, Categorizing and Detailing Recomendation, dan Budgeting and Analysis (Peter Chen, dkk, 2004). Perbedaan penelitian ini adalah objek penelitian lain adalah terfokus pada analisis perancangan aplikasi e-commrece dengan mengimplementasikan metode square yang dikenalkan oleh Carnegie Mellon Software Engineering Institute dalam menjamin keamanan serta keberlangsungan sistem dan aplikasi berbasis Teknologi Informasi dalam sebuah Sistem Manajemen Aset.

Penelitian ini penting dilakukan karena diharapkan dapat membantu organisasi atau perusahaan dalam menjamin keamanan serta keberlangsungan sistem dan aplikasi khususnya sistem aplikasi $e$-commerce.

\section{METODE}

Penelitian menggunakan metode System Quality Engineering Requirement (SQUARE) dalam menganalisis dan perancangan sistem aplikasi e-commerce Business to Costumer (B2C). Tahapan ini meliputi proses teknik untuk melakukan identifikasi kebutuhan, analisis, spesifikasi, dan manajemen aset. Metode System Quality Engineering Requirement (SQUARE) juga berfokus pada isu-isu manajemen yang terkait dengan perkembangan keamanan sistem dan menjadikan persyaratan privasi sistem IT yang baik. 


\section{HASIL DAN PEMBAHASAN}

Dalam hasil dan pembahasan penelitian ini hanya menggunakan beberapa langkah metodologi

System Quality Engineering Requirement (SQUARE) yang digunakan salah satunya:

\section{Definitions}

Mendefnisikan istilah keamanan sistem yang telah disepakati dan umum ditemukan dalam sistem. Istilah keamanan sistem tersebut sebagai berikut:

- FTP Bounce Attack yakni dengan menggunakan server ftp orang lain untuk melakukan serangan pada sistem.

- Distributed DoS (DDoS), salah satu jenis serangan Denial of Service yang menggunakan banyak host penyerang (baik itu menggunakan komputer yang didedikasikan untuk melakukan penyerangan atau komputer yang "dipaksa" menjadi zombie) untuk menyerang satu buah host target dalam sebuah jaringan yang terhubung.

- Serangan Injeksi SQL, pada serangan ini objek yang diserang adalah halaman web yang menggunakan Structured Query Language ( $S Q L)$ untuk melakukan query dan memanipulasi database yang dikostumisasi.

- Password Attack, serangan untuk meng-crack sebuah password pada sistem.

\section{Safety \& Security Goals}

Menganalisis tujuan keamanan Sistem e-commerce, untuk memastikan keamanan secara keseluruhan sistem e-commerce dan ketersediaan (availability) data.

Adapun tujuannya sebagai berikut:

- Melakukan pengontrolan secara efektif saat dilakukan pengkonfigurasian sistem dan penggunaan sistem.

- Kerahasiaan, akurasi, integritas dan keamanan data dalam sistem harus terjamin keasliannya.

- Sistem e-commerce harus tersedia baik data transaksi yang aman dan data pengguna yang sesuai.

\section{System Architecture}

Dengan menggunakan dua firewall, firewall pertama menjadi pembatas autentikasi masuknya penguna sistem pada jaringan internal/lokal dan firewall kedua menjadi pembatas autentikasi masuknya penguna sistem ke web server.

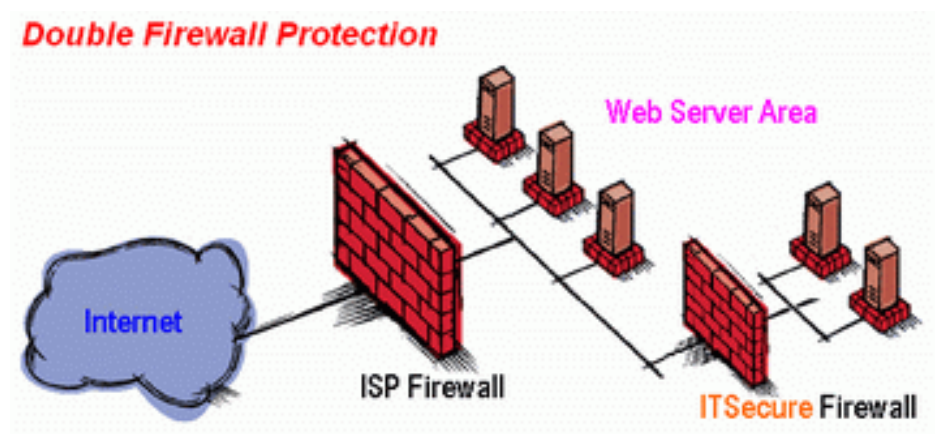

Gambar 1. Double Firewall Protection

\section{Use Case}

Menggambarkan diagram Use Case aplikasi menggunakan UML (Unified Modeling Language). 
Faktor Exacta 11 (4): 332-339, 2018

p-ISSN: 1979-276X

Ismawan, dkk - Analisis dan Perancangan E-commerce...

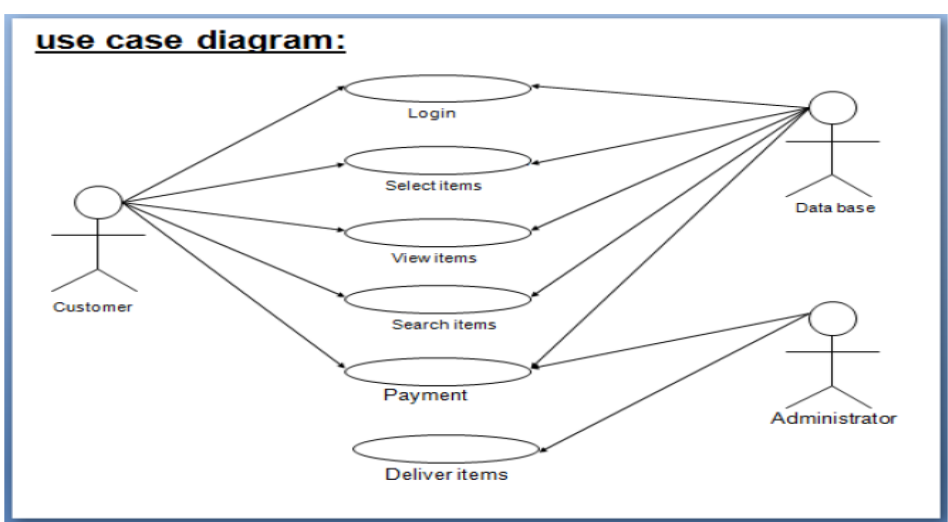

Gambar 2. Use Case Perancangan E-commerce

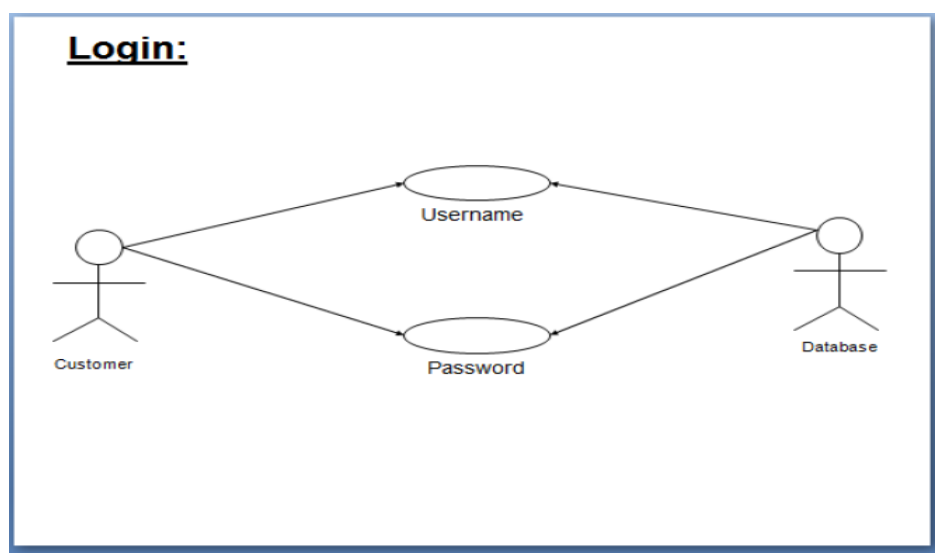

Gambar 3. Use Case Login Perancangan Sistem E-commerce

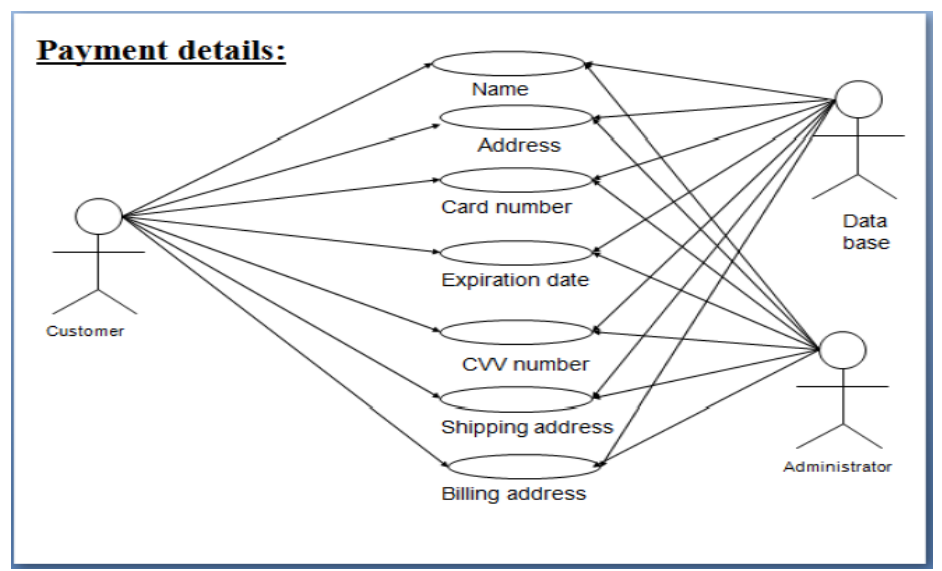

Gambar 4. Use Case Payment Details Perancangan Sistem E-commerce

\section{Misuse Cases}

Mengidentifikasi kemungkinanan ancaman potensi penyalahgunaan aplikasi yang disepakati dalam organisasi. 
Faktor Exacta 11 (4): 332-339, 2018

p-ISSN: 1979-276X

Ismawan, dkk - Analisis dan Perancangan E-commerce...

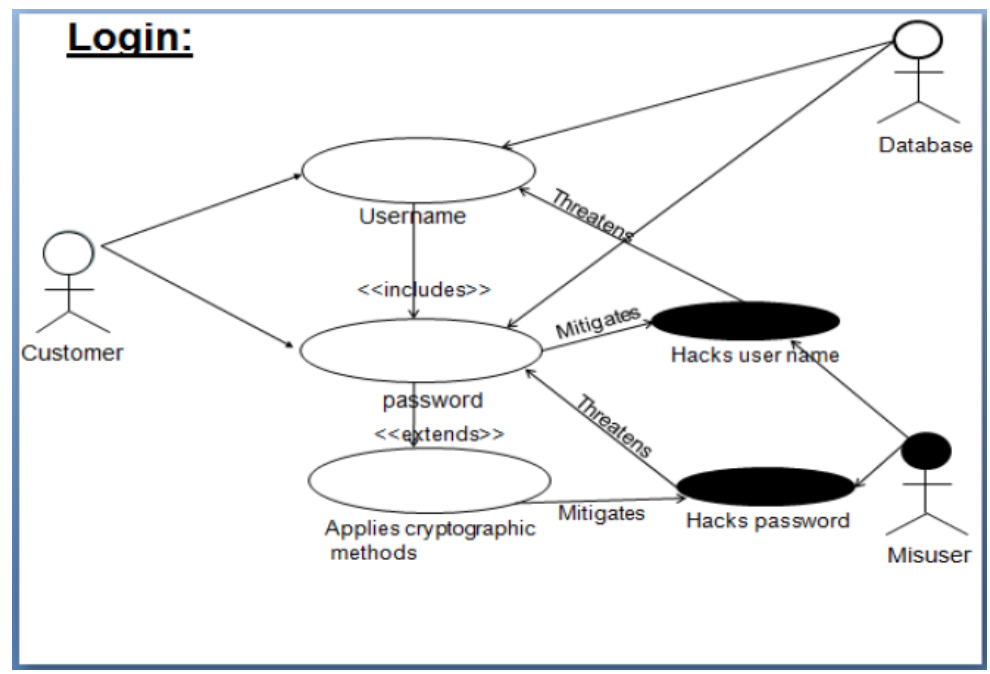

Gambar 5. Misuse Case Login Perancangan Sistem E-commerce

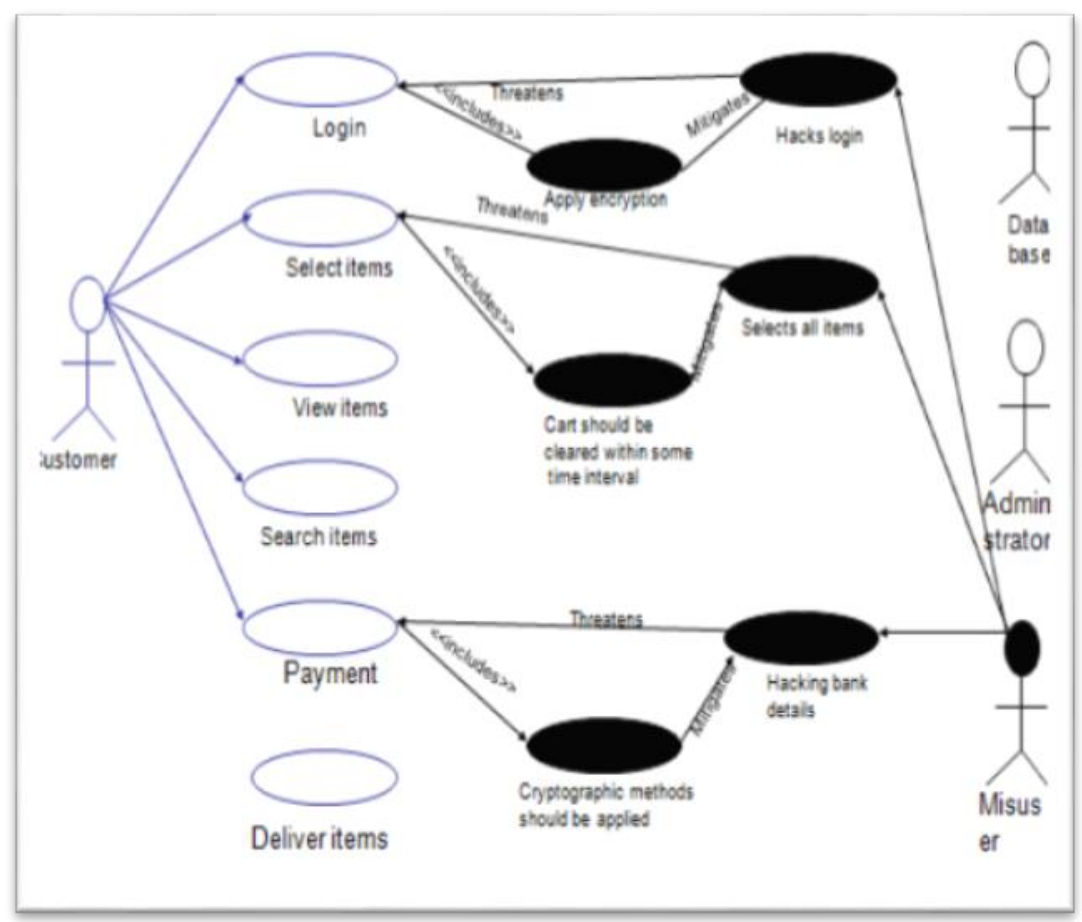

Gambar 6. Misuse Case Perancangan Sistem E-commerce

\section{Attack Tree}

Representasi hirarkis banyak jenis pelanggaran keamanan yang didasarkan kepada misuse case. 


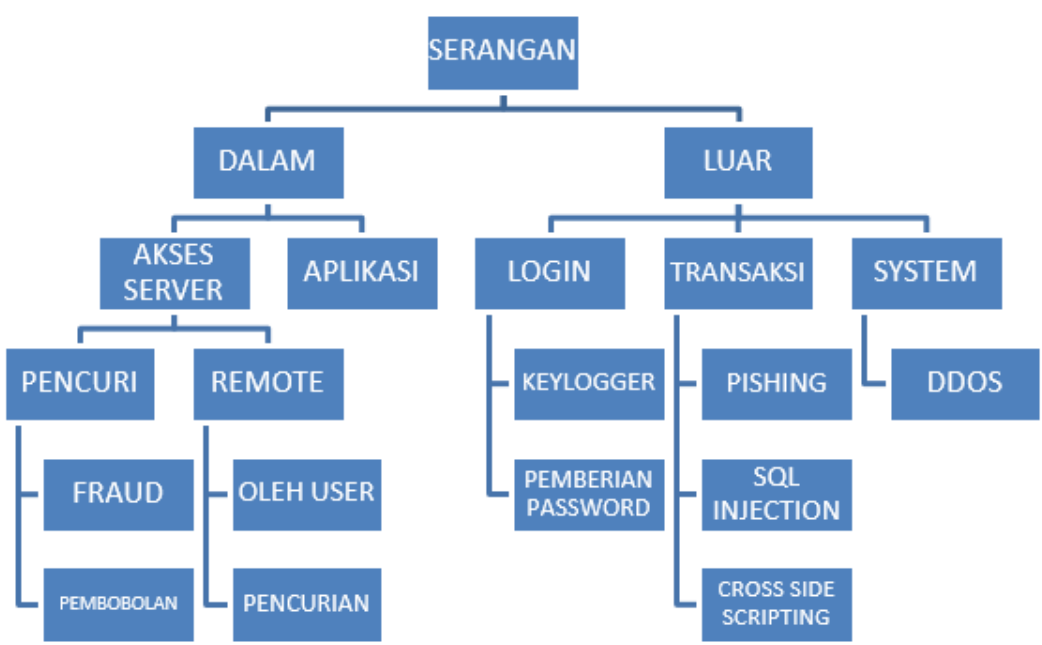

Gambar 7. Attack Tree Perancangan Sistem E-commerce

\section{Prioritization}

Untuk memprioritaskan persyaratan keselamatan dan keamanan digunakan misuse case dan kategorinya.

Tabel 1. Use Case Prioritas

\begin{tabular}{|c|c|c|}
\hline Nama & Use Case & Prioritas \\
\hline Login & UC-01 & High \\
\hline Select Item & UC-02 & High \\
\hline View Items & UC-03 & Medium \\
\hline Search Items & UC-04 & Low \\
Payment & UC-05 & High \\
\hline Deliver Items & UC-06 & Medium \\
\hline
\end{tabular}

Tabel 2. Misuse Case Prioritas

\begin{tabular}{|c|c|c|}
\hline Nama & Misuse Case & Prioritas \\
\hline Hacks Login & MU-01 & High \\
\hline Select All Items & MU-02 & Medium \\
\hline Hacking Bank Details & MU-03 & High \\
\hline
\end{tabular}

Flow Diagram Kerja System Quality Engineering Requirement (SQUARE)

Flow diagram ini merupakan kerja System Quality Engineering Requirement (SQUARE) yang dilakukan sebagai solusi keamanan aplikasi e-commerce Business to Costumer (B2C) 


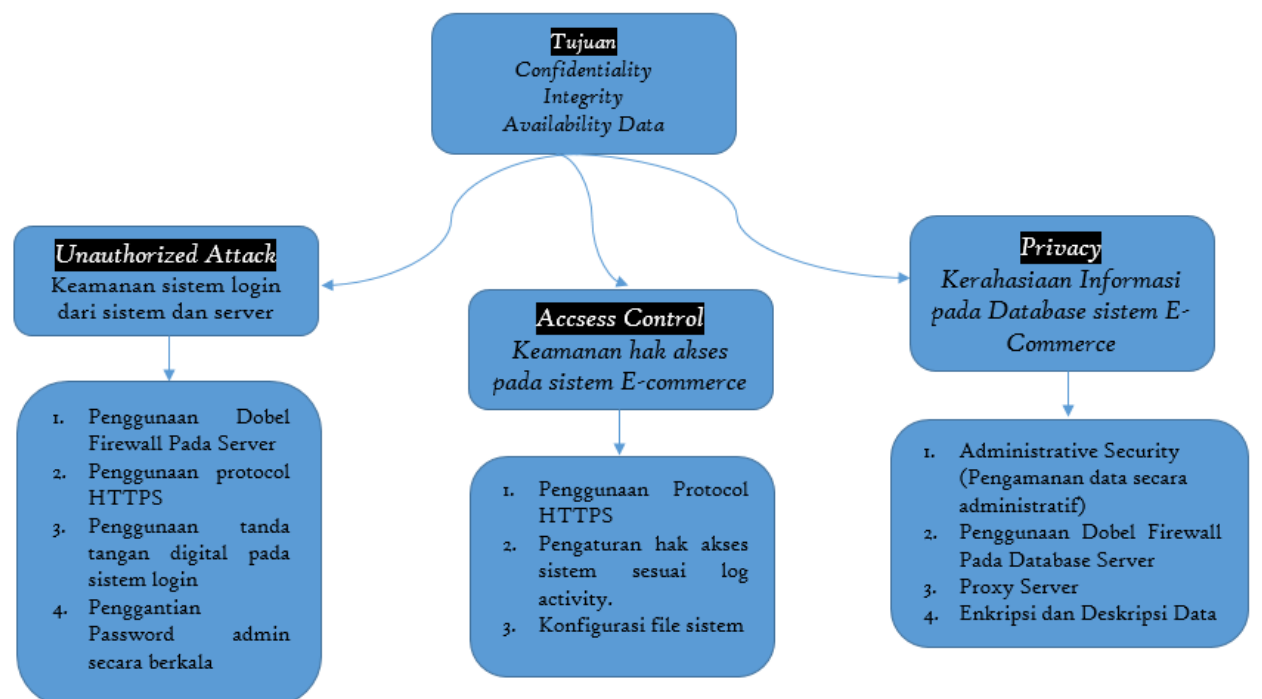

Gambar 8. Flow Diagram Cara Kerja System Quality Engineering Requirement (SQUARE)

Setelah melakukan proses analisis perancangan sistem e-commerce metode System Quality Engineering Requirement (SQUARE), berikut prototipe Sistem E-commerce yang akan di rancang.

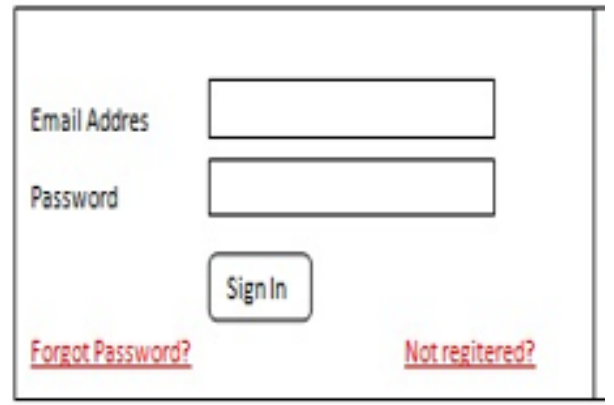

Gambar 9. Rancangan Prototipe Login Sistem E-commerce

\section{PENUTUP}

\section{Simpulan}

Berdasarkan hasil penelitian ini disimpulkan bahwa dengan menggunakan Metode SQUARE sistem keamanan website E-commerce menjadi lebih terstruktur dan terukur, administrator dapat mengenali jenis ancaman serta mengetahui bagaimana cara mengatasinya dengan menggunakan skala prioritas, rekomendasi yang diberikan sudah cukup memberikan solusi untuk ancaman yang mungkin terjadi pada website e-commerce, serta dapat menjamin keamanan dan keberlangsungan sistem aplikasi berbasis Teknologi Informasi khususnya $e$-commerce.

\section{DAFTAR PUSTAKA}

Albaar, A. H. (2016) Komparasi Perangkat Lunak High - Fidelity Prototyping : Justinmind dan Mockplus dalam Pengembangan Aplikasi Web dan Mobile E - government (Studi Kasus : LPSE). Universitas Islam Indonesia.

Munawar, Kholil. 2009. E-commerce. http://staff.uns.ac.id. 
Faktor Exacta 11 (4): 332-339, 2018

p-ISSN: 1979-276X

e- ISSN: 2502-339X

DOI : 10.30998/faktorexacta.v11i4.2841

Ismawan, dkk - Analisis dan Perancangan E-commerce...

Laudon, Kenneth C, dkk, 2007, Sistem Informasi Manajemen Edisi 10 Buku 2, Salemba Empat, Jakarta

System Quality Requirements Engineering (SQUARE) Methodology: Case Study on Asset Management System (Peter Chen, Marjon Dean, Don Ojoko-Adams, Hassan Osman, Lilian Lopez, Nick Xie ; Nancy R. Mead, Advisor. Desember 2004)

Onno W Purbo dan Aang Arif Wahyudi. 2001. Mengenal E-commerce. Jakarta: Elex Media Komputindo. 